\title{
Prevalence and Correlates of Receiving and Sharing High-Penetrance Cancer Genetic Test Results: Findings from the Health Information National Trends Survey
}

\author{
Jennifer M. Taber ${ }^{a}$ Christine Q. Chang ${ }^{a} \quad$ Tram K. Lam $^{a} \quad$ Elizabeth M. Gillanders ${ }^{a}$ \\ Jada G. Hamilton ${ }^{b}$ Sheri D. Schully ${ }^{a}$ \\ a Division of Cancer Control and Population Sciences, National Cancer Institute, National Institutes of Health, \\ Bethesda, Md., and ${ }^{\mathrm{b}}$ Department of Psychiatry and Behavioral Sciences, Memorial Sloan Kettering Cancer Center, \\ New York, N.Y., USA
}

\section{Key Words \\ BRCA1/2 - Communication of test results - Genetic testing . Health Information National Trends Survey · Hereditary cancer $\cdot$ Hereditary nonpolyposis colorectal cancer $\cdot$ Lynch syndrome}

\begin{abstract}
Background/Aims: The aim of this study was to explore the prevalence and correlates of receiving and sharing high-penetrance cancer genetic test results. Methods: Participants completed the population-based, cross-sectional 2013 Health Information National Trends Survey. We examined sociodemographic characteristics of participants reporting having had BRCA1/2 or Lynch syndrome genetic testing, and sociodemographic and psychosocial correlates of sharing test results with health professionals and family members. Results: Participants who underwent BRCA1/2 or Lynch syndrome genetic testing ( $n=77 ; 2.42 \%$ of respondents) were more likely to be female and to have a family or personal history of cancer than those not undergoing testing. Approximately three-quarters of participants shared results with health professionals and three-quarters with their family; only $4 \%$ did not share results with anyone. Participants who shared results with health professionals reported greater op-
\end{abstract}

timism, self-efficacy for health management, and trust in information from their doctors. Participants who shared results with their family were more likely to be female and to have a personal history of cancer, and had greater self-efficacy for health management, perceived less ambiguity in cancer prevention recommendations, and lower cancer prevention fatalism. Conclusions: We identified several novel psychosocial correlates of sharing genetic information. Health professionals may use this information to identify patients less likely to share information with at-risk family members.

(c) 2014 S. Karger AG, Basel

\section{Introduction}

Genetic testing for familial cancer syndromes is one of the most utilized applications in genetic medicine. Currently, professional societies and evidence review panels support BRCA1 and BRCA2 mutation testing for risk of hereditary breast and ovarian cancers, and Lynch syndrome mutation testing for risk of colorectal and endometrial cancers (also known as hereditary nonpolyposis

J.G.H. and S.D.S. are both senior authors.

\section{KARGER 125}

(c) 2014 S. Karger AG, Base

$1662-4246 / 14 / 0182-0067 \$ 39.50 / 0$

E-Mail karger@karger.com

www.karger.com/phg
Jennifer M. Taber, PhD

Division of Cancer Control and Population Sciences, National Cancer Institute National Institutes of Health, 9609 Medical Center Drive, Room 3E642 Bethesda, MD 20892-9761 (USA)

E-Mail Jennifer.taber@nih.gov 
colorectal cancer) for clinical use [1-3]. Criteria for $B R C A 1 / 2$ genetic testing are varied but include factors such as early onset of personal history of breast cancer, a family history of male breast cancer, or a family member with a known mutation [1]. The Evaluation of Genomic Applications in Practice and Prevention Working Group recommends genetic testing for Lynch syndrome for all individuals with newly diagnosed colorectal cancer [2]. Patients who learn genetic test results, especially if the results confer elevated risk, may be able to better understand their lifetime cancer risk and to make informed decisions about screening and prevention options.

Whether these patients communicate their genetic test results to others can have important implications for themselves and their family members. For example, communicating test results to primary care physicians and other providers outside of tertiary care may facilitate appropriate cancer prevention strategies, including screening and behavioral interventions. Furthermore, informing biological relatives of test results and risk information can allow family members to decide whether to pursue genetic counseling and testing for themselves. A review of the literature determined that between 13 and $64 \%$ of family members informed of risk information sought genetic testing for themselves [4]. Thus, an important step in reaching the full potential of genetic applications is communicating test results.

Research on the communication of genetic test results with health professionals has primarily been conducted in the context of direct-to-consumer (DTC) testing. While the prevalence of sharing DTC test results with a healthcare provider varies considerably, it is consistently lower than communication of results to family members [5-8]. Findings from studies in various testing contexts, including DTC, suggest that many factors are associated with greater likelihood of disclosing results to a physician. These factors include an individual's test result, sociodemographic characteristics (e.g. older age, higher education, greater income), medical factors (e.g. history of regular medical exams, personal history of cancer), and perceived cancer risk (e.g. perceptions of poor health, greater perceived risk of cancer before undergoing genetic testing) [5-11]. Participants who intended to share genetic test results with family members were also more likely to share results with a healthcare provider [12].

A range of factors associated with whether individuals share genetic test results with family members has also been identified, primarily among individuals who received genetic testing while participating in a research study [13-15]. For BRCA1/2 and Lynch syndrome, indi- vidual-level factors associated with greater likelihood of sharing test results with family members included the nature of the test results, such that positive test results were more likely to be disclosed than negative or uninformative results $[13,16,17]$, and the individual's sociodemographic characteristics (e.g. being female, being White $[18,19])$. Several individual-level factors including preferences and knowledge have also been explicitly reported as reasons for sharing test results in qualitative studies or found to be statistically associated with sharing. These factors include greater need for emotional support [20], feelings of duty or responsibility [13, 14, 21, 22], greater knowledge or understanding of screening and risk reduction strategies or test results $[18,20]$, and higher baseline self-efficacy for coping with the test result [12]. Factors relating to family dynamics and family members' anticipated responses have also been reported as reasons for sharing, including perceiving that relatives are emotionally ready [23] and able to understand the information [17], closeness with family members [13, 17, 20, 22], having relatives previously diagnosed with cancer [21], and perceiving that information would help certain relatives to make their own decisions [20].

We know of no research that has examined psychological factors such as optimism or numeracy, or attitudes about cancer (such as whether it is preventable or whether cancer prevention recommendations are easy to understand), as correlates of sharing test results. Moreover, limited research has examined how individuals share genetic test results outside of the context of research studies in which participants benefit from state-of-the-art counseling and behavioral recommendations that often accompany receipt of test results. To address these gaps, we examined national data collected from the populationbased Health Information National Trends Survey (HINTS 4, Cycle 3) to explore prevalence and correlates of both receiving and sharing genetic test results for $B R C A 1 / 2$ mutations and Lynch syndrome. We examined sociodemographic and medical factors that have been associated with sharing test results (e.g. age, gender, personal history of cancer) in prior empirical work. Given that recent theoretical work has highlighted the relevance of an individual's personal characteristics and the quality of her/his relationships to the decision to disclose genetic test results [14], we also examined whether novel psychological factors, including optimism, numeracy, self-efficacy for managing one's health, perceived ambiguity in cancer prevention recommendations, cancer fatalism, and trust in health information from doctors and family members, were associated with sharing high-penetrance
68

Public Health Genomics 2015;18:67-77 DOI: $10.1159 / 000368745$
Taber/Chang/Lam/Gillanders/Hamilton/ Schully 
cancer genetic test results. The results from the present study should be considered exploratory due to the small sample size; nevertheless, this study presents the first exploration of these factors in the general US population.

\section{Materials and Methods}

\section{Study Design and Population}

HINTS is a cross-sectional national survey that has been administered periodically by the National Cancer Institute since 2003. HINTS data are used to assess how people access and use health information and technology to manage their health, and their engagement in health behaviors. The most recent version (HINTS 4) includes 4 data collection cycles over the course of 3 years. We report data from Cycle 3 which was conducted from September through December 2013, completed by 3,185 individuals, and included a series of questions on genetic testing and family history. Details of the study design are available elsewhere [24].

Measures

Genetic Testing Engagement and Sharing

Receipt of genetic testing was measured in response to the item, 'Have you ever had any of the following type(s) of genetic tests? Mark all that apply' with response options of paternity testing, ancestry testing, DNA fingerprinting, Cystic Fibrosis carrier testing, $B R C A 1 / 2$ testing, Lynch syndrome testing, and other. The present study focused on cancer-related genetic tests: BRCA1/2 (described as testing 'to determine if a person has more than an average chance of developing breast cancer or ovarian cancer') and Lynch syndrome (described as testing 'to determine if a person has more than an average chance of developing colon cancer').

Data on sharing test results were obtained from responses to the item, 'If you had a genetic test, with whom did you personally share the results? Mark all that apply' with the following response options: health professional, family member, friend, other, did not have this type of test, and did not communicate the results.

\section{Sociodemographic Factors}

We examined selected sociodemographic factors including age, gender, income, education, and race and ethnicity. Marital status was dichotomized as those who indicated being married or living as married versus those who indicated being divorced, widowed, separated, or single, never been married. Presence of children $<18$ years of age living in the household was derived from the number reported in response to: 'How many children under the age of 18 live in your household?'

\section{Medical Factors}

Family history of cancer was assessed with the item, 'Have any of your family members ever had cancer?' (yes, no, or not sure). Personal history of cancer was assessed with the item, 'Have you ever been diagnosed as having cancer?' (yes, no). Participants who indicated having had only nonmelanoma skin cancer in response to a follow-up question assessing type of cancer were categorized as not having a personal history of cancer. Health insurance status was dichotomized based on whether participants indicated having one of multiple types of health insurance (yes, no). Access to a regular provider was assessed with the item, 'Not including psychiatrists and other mental health professionals, is there a particular doctor, nurse, or other health professional that you see most often?' (yes, no).

Two HINTS items assessed prior engagement with and attitudes toward medical research. Prior engagement in medical research was measured by an item assessing whether participants had ever engaged in medical research by 'partnering with medical researchers to help decide what research is done and how it is done' (yes, no, or not sure). Completion of the HINTS survey did not count as prior engagement, and an item assessing more traditional participation (rather than partnership) in medical research was not included in HINTS. Attitudes toward medical research were assessed as agreement with the item, 'Medical research provides information that people need to make medical decisions' from 1 (strongly disagree) to 4 (strongly agree). Because the distribution was skewed, responses were dichotomized as 1 (strongly agree) or 0 (somewhat agree, somewhat disagree, or strongly disagree).

Quality of communication was assessed as the average of 7 items $(\alpha=0.94)$ indicating the frequency at which 'all doctors, nurses, or other health professionals you saw during the past 12 months' were responsive to patient needs and concerns (i.e. gave you the chance to ask all health-related questions you had, gave the attention you needed to your feelings and emotions, involved you in decisions about health care as much as you wanted, made sure you understood the things you needed to do to take care of your health, explained things in a way you could understand, spent enough time with you, and helped you deal with feelings of uncertainty about your health or health care) from 1 (never) to 4 (always).

\section{Psychological Factors}

Dispositional optimism was assessed as agreement with one item from the LOT-R, 'I'm always optimistic about my future' from 1 (strongly disagree) to 5 (strongly agree) [25]. Numeracy was assessed as the number of math-related questions about a nutrition label (out of 4) that participants answered correctly [26]. Self-efficacy for health management was assessed with the item, 'Overall, how confident are you about your ability to take good care of your health?' from 1 (completely confident) to 5 (not confident at all). Perceived ambiguity in cancer prevention recommendations was assessed with the item, 'There are so many different recommendations about preventing cancer, it's hard to know which ones to follow' from 1 (strongly disagree) to 4 (strongly agree). Cancer prevention fatalism, or beliefs about the inability to reduce cancer risk, was assessed with the item, 'There's not much you can do to lower your chances of getting cancer' from 1 (strongly disagree) to 4 (strongly agree). This operationalization of cancer prevention fatalism is consistent with prior research [27] and definitions of fatalism [28]. Trust in information from doctors and family were assessed with 2 single items, respectively: 'In general, how much would you trust information about health or medical topics from each of the following? (A) a doctor, and (B) family or friends', from 1 (not at all) to 4 (a lot). Responses to these psychological factors were treated as continuous variables.

Perceived value of family health history was assessed with the item, 'How important is it to know your family's health history for your own health?' from 1 (not at all important) to 4 (very important). Because the distribution was skewed, responses were dichotomized ( 1 = very important; $0=$ moderately, slightly, or not at all important). 
Statistical Analyses

First, we evaluated sociodemographic and medical characteristics of participants who reported having had BRCA1/2 or Lynch syndrome genetic testing and used $\chi^{2}$ analyses and t-tests to compare these respondents to those who did not have either of these genetic tests. Next, among those who had BRCA1/2 or Lynch syndrome genetic testing, we examined the proportion who shared results with health professionals and family members. We used $\chi^{2}$ analyses and t-tests to examine bivariate associations of sociodemographic, medical history, and psychological factors with sharing test results. Last, we conducted multivariable logistic regression analyses to examine whether the psychological factors that were significantly associated with sharing results in bivariate analyses remained significant when controlling for certain sociodemographic factors. Multivariable logistic regression analyses were used to obtain an odds ratio (OR) and 95\% confidence interval (CI). All models included the following sociodemographic and medical history covariates: age, education, income, gender, race (non-Hispanic White vs. not non-Hispanic White), and family and personal history of any cancer. Health insurance was not included in these analyses because of its low variability, and marital status and presence of children were not included because they were unassociated with sharing of results. A statistical significance criterion of $\mathrm{p}<0.05$ was used for all analyses, and results at $\mathrm{p}<0.10$ are noted as marginally significant. Because of missing data, sample sizes for these multivariable analyses ranged from 56 to 58 . All analyses were conducted using SPSS 21.0.

We also note that typical analysis of HINTS data involves using weights to approximate nationally representative estimates. Because of the small sample sizes, we were unable to use weights as the results became unstable with their application. We report results using pairwise deletion of participants who did not provide valid answers to individual items.

\section{Results}

\section{Sample Characteristics}

Of the 3,185 respondents who completed the HINTS survey, 135 participants (4.24\% of HINTS respondents) reported having had either $B R C A 1 / 2$ or Lynch syndrome testing. Of these, 58 respondents were excluded from analyses because they (1) responded 'Did not have this type of test' when asked with whom they shared their test results $(\mathrm{n}=41)$, or $(2)$ did not respond to the item about sharing test results $(\mathrm{n}=17)$. The final analytical sample consisted of 77 participants $(2.42 \%$ of HINTS respondents). Comparisons of the 58 excluded individuals with those included in the final analytical sample demonstrated that those excluded were more likely to be male $\left[\chi^{2}\right.$ $(1)=4.24, p=0.040]$ and less likely to have a personal history of cancer $\left[\chi^{2}(1)=10.00, p=0.002\right]$.

Of the 77 respondents who reported cancer genetic testing, 58 reported $B R C A 1 / 2$ testing and 35 reported Lynch syndrome testing, with 16 reporting having had both
BRCA1/2 and Lynch syndrome testing. Table 1 presents demographic characteristics of those who reported having had BRCA1/2 or Lynch syndrome genetic testing compared to those who did not. Participants who had either $B R C A 1 / 2$ or Lynch syndrome genetic testing were mostly female $(75.3 \%)$ and had more than a high school education (63.6\%). Approximately half reported a household income of USD $<35,000(41.6 \%)$ and were non-Hispanic White (52.0\%). The median age was $54.5(\mathrm{M}=55.3$, range $=25$ 93 years). Approximately half (42.9\%) had a personal history of any cancer $(27.6 \%$ breast cancer, $3.9 \%$ colon cancer) and most had a family history of cancer $(86.5 \%)$. The majority (66.2\%) agreed that medical research provides information that people need to make medical decisions, with $8 \%$ reporting prior engagement in medical research.

As shown in the rightmost column of table 1, participants who underwent either BRCA1/2 or Lynch syndrome genetic testing compared to those who did not were more likely to be female, to have a family and personal history of cancer, to have health insurance, and to have been engaged in medical research.

\section{Prevalence of Sharing Genetic Test Results}

Most respondents who underwent $B R C A 1 / 2$ or Lynch syndrome genetic testing shared their results with health professionals (72.7\%) and family members (75.3\%). As shown in figure 1, approximately half of participants shared their results with both health professionals and family members, with a subset only sharing their results with one of these targets. Three respondents (3.9\%) reported not communicating their test results to anyone. A subset $(27.3 \%$, not shown) indicated sharing their results with a friend or 'other', all of whom also shared their results with a health professional and/or family member.

\section{Correlates of Sharing Genetic Test Results with Health}

\section{Professionals and Family Members}

Health Professionals

As shown in table 2, no sociodemographic or medical factors were significantly associated with sharing results with health professionals. Several psychological factors were significantly associated with greater likelihood of sharing results with health professionals: being higher in optimism, reporting greater self-efficacy for health management, and reporting greater trust in health information from doctors.

\section{Family Members}

Participants who reported sharing their test results with family members were more likely to be female, to 
Table 1. Sociodemographic and medical factors among participants who did and did not report having had BRCA1/2 or Lynch syndrome genetic testing

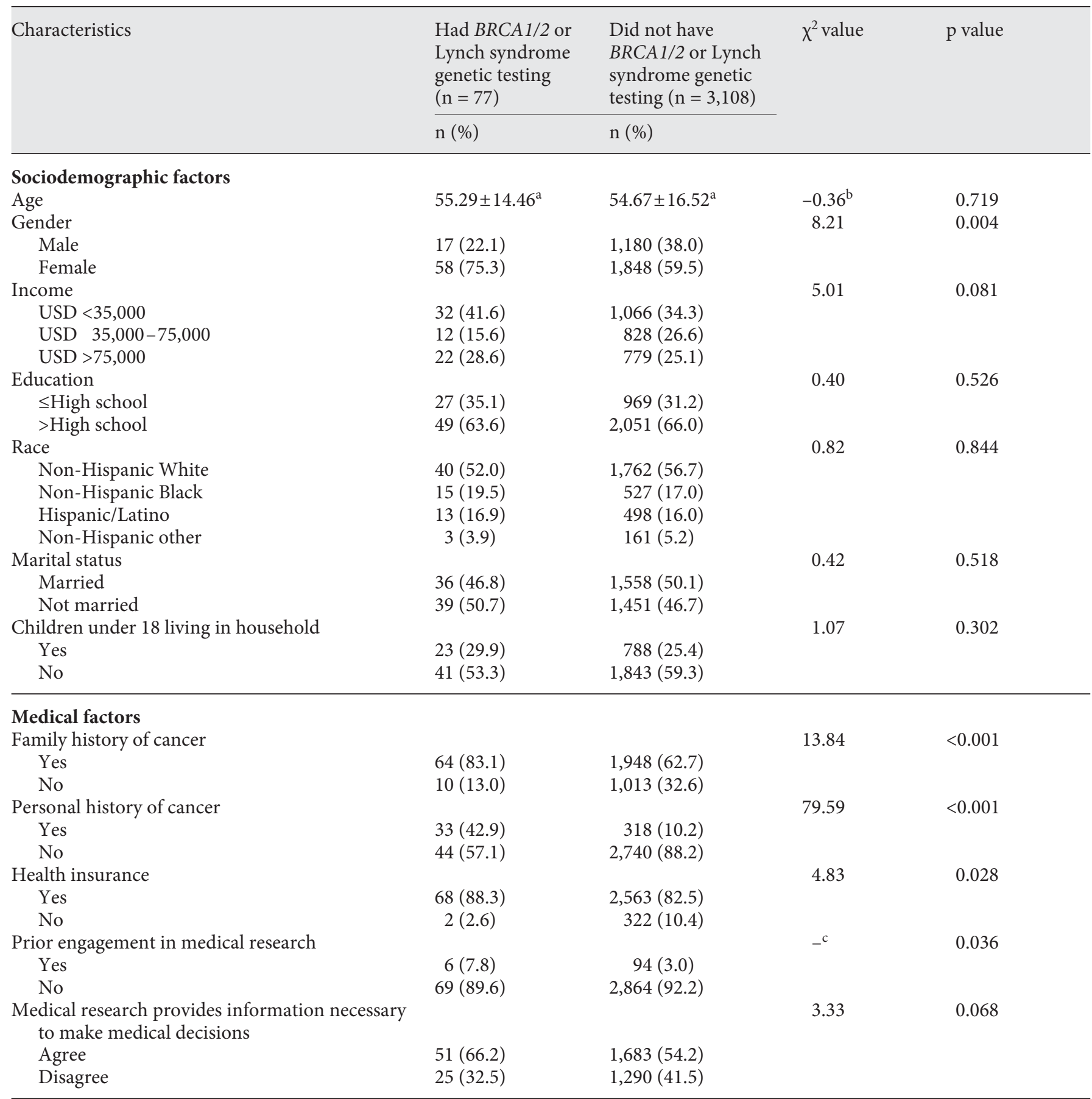

${ }^{a}$ Mean age $\pm \mathrm{SD}$, years. ${ }^{\mathrm{b}}$ t test value. ${ }^{\mathrm{c}}$ Fisher's exact test computed because at least 1 cell had an expected count less than 5 .

Correlates of Sharing Cancer Genetic Test Results 
Target of sharing genetic test results $(n=77)$

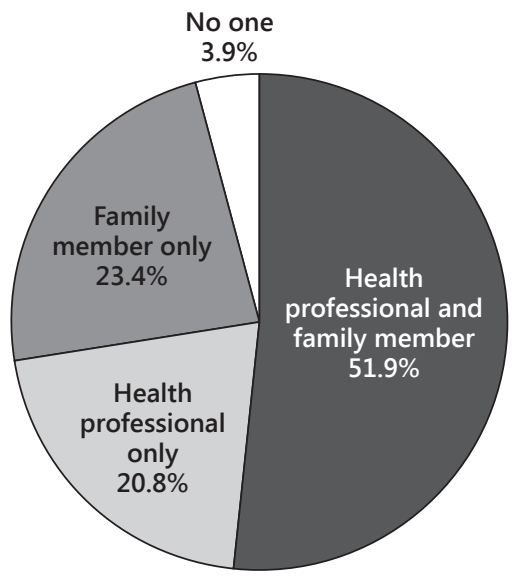

Fig. 1. Proportion of respondents sharing cancer genetic test results with a health professional and family member, a health professional only, a family member only, or with no one.

have higher income, to be non-Hispanic White, and to have a personal history of cancer (table 2). In terms of psychological factors, participants who shared their results with family members reported greater self-efficacy for health management, lower perceived ambiguity in cancer prevention recommendations, and lower cancer prevention fatalism.

\section{Multivariable Associations of Sharing Results with}

Psychological Factors

All of the psychological factors identified as bivariate correlates of sharing test results with health professionals remained significant or marginally so when entered in logistic regressions controlling for sociodemographic and medical history factors (separate analyses were conducted for each psychological factor, as we sought to determine whether the effects were confounded by sociodemographic factors rather than to test these factors against each other). Specifically, sharing test results with health professionals was associated with greater optimism $(\mathrm{OR}=2.23,95 \% \mathrm{CI}=0.92-5.39, \mathrm{p}=0.076)$, greater selfefficacy for health management $(\mathrm{OR}=1.88,95 \% \mathrm{CI}=$ $0.92-3.85, p=0.083$ ), and greater trust in health informa- tion from doctors $(\mathrm{OR}=6.48,95 \% \mathrm{CI}=1.63-25.68, \mathrm{p}=$ $0.008)$. In all 3 analyses, no sociodemographic or medical history factors were significantly associated with result sharing.

Similarly, all previously significant correlates of sharing test results with family members remained significant when controlling for sociodemographic and medical history factors: self-efficacy for health management $(\mathrm{OR}=$ $4.33,95 \% \mathrm{CI}=1.13-16.58, \mathrm{p}=0.033)$, perceived ambiguity in cancer prevention recommendations $(\mathrm{OR}=0.01$, $95 \% \mathrm{CI}=0.00-0.33, \mathrm{p}=0.012)$, and cancer prevention fatalism $(\mathrm{OR}=0.23,95 \% \mathrm{CI}=0.06-0.90, \mathrm{p}=0.034)$. Sociodemographic and medical factors had inconsistent associations with sharing across these analyses. When selfefficacy for health management was included in the model, gender, race, and personal history of cancer were all marginally significant correlates (all $\mathrm{p}<0.10$ ). When perceived ambiguity was included in the model, gender and race were significant correlates (all $\mathrm{p}<0.05$ ) and family and personal history of cancer were marginally significant (all $\mathrm{p}<0.09$ ). When cancer prevention fatalism was included in the model, only race was significantly associated with sharing $(\mathrm{p}=0.036)$.

\section{Discussion}

The present study reports the prevalence of receiving and sharing BRCA1/2 and Lynch syndrome genetic test results using data collected from a national survey. The majority of respondents shared their test results with either a health professional or a family member. Participants were more likely to share their results with health professionals if they were higher in optimism, reported greater self-efficacy for health management, and reported greater trust in health information from doctors. We identified several novel correlates of sharing test results with family members, including greater self-efficacy for health management, lower perceived ambiguity in cancer prevention recommendations, and lower cancer prevention fatalism.

In $2010, \sim 47 \%$ of the population was aware of cancer genetic testing according to data from a national survey [29], and in 2011, 35\% of the population was aware of DTC genetic testing [30]. Although such studies suggest moderate levels of awareness of genetic tests in the general population, only $2.42 \%$ of the present populationbased sample reported having had either BRCA1/2 or Lynch syndrome genetic testing. Because it is unknown what proportion of this HINTS sample meets the recom-
Taber/Chang/Lam/Gillanders/Hamilton/ Schully 
Table 2. Bivariate associations among sociodemographic, medical, and psychological factors, and sharing of cancer genetic test results

\begin{tabular}{|c|c|c|c|c|c|c|c|c|}
\hline \multirow[t]{2}{*}{ Characteristics } & \multicolumn{4}{|c|}{ Health professional } & \multicolumn{4}{|l|}{ Family member } \\
\hline & $\begin{array}{l}\text { shared results, } \\
\mathrm{n}=56 \\
\mathrm{n}(\%)\end{array}$ & $\begin{array}{l}\text { did not share } \\
\text { results, } \mathrm{n}=21\end{array}$ & $x^{2}$ value & $\mathrm{p}$ value & $\begin{array}{l}\text { shared results, } \\
\mathrm{n}=58 \\
\mathrm{n}(\%)\end{array}$ & $\begin{array}{l}\begin{array}{l}\text { did not share } \\
\text { results, } \mathrm{n}=19\end{array} \\
\mathrm{n}(\%)\end{array}$ & $\chi^{2}$ value & $\mathrm{p}$ value \\
\hline \multicolumn{9}{|l|}{ Sociodemographic factors } \\
\hline Age & $54.36 \pm 14.33^{\mathrm{a}}$ & $57.90 \pm 14.89^{\mathrm{a}}$ & $0.91^{b}$ & 0.364 & $55.15 \pm 15.15^{\mathrm{a}}$ & $55.68 \pm 12.69^{\mathrm{a}}$ & $0.14^{\mathrm{b}}$ & 0.891 \\
\hline Gender & & & $-^{c}$ & 1.000 & & & $-^{c}$ & 0.001 \\
\hline Income & & & $-c, d$ & 0.413 & & & $-c, d$ & 0.021 \\
\hline USD $<35,000$ & $25(44.6)$ & $7(33.3)$ & & & $20(34.5)$ & $12(63.2)$ & & \\
\hline USD $35,000-75,000$ & $7(12.5)$ & $5(23.8)$ & & & $11(19.0)$ & $1(5.3)$ & & \\
\hline USD > 75,000 & $16(28.6)$ & $6(28.6)$ & & & $19(32.8)$ & $3(15.8)$ & & \\
\hline Education & & & 0.08 & 0.772 & & & 3.24 & 0.072 \\
\hline$\leq$ High school & $19(33.9)$ & $8(38.1)$ & & & $17(29.3)$ & $10(52.6)$ & & \\
\hline Non-Hispanic other & $2(3.6)$ & $1(4.8)$ & & & $2(3.4)$ & $1(5.3)$ & & \\
\hline Marital status & & & 0.10 & 0.754 & & & 1.27 & 0.260 \\
\hline Married & $27(48.2)$ & $9(42.9)$ & & & $29(50.0)$ & $7(36.8)$ & & \\
\hline Not married & $28(50.0)$ & $11(52.4)$ & & & $27(46.6)$ & $12(63.2)$ & & \\
\hline $\begin{array}{l}\text { Children under } 18 \text { living in } \\
\text { household }\end{array}$ & & & 0.10 & 0.758 & & & 1.54 & 0.215 \\
\hline Yes & $16(28.6)$ & $7(33.3)$ & & & $16(27.6)$ & $7(36.8)$ & & \\
\hline No & $30(53.6)$ & $11(52.4)$ & & & $34(58.6)$ & $7(36.8)$ & & \\
\hline \multicolumn{9}{|l|}{ Medical factors } \\
\hline Family history of cancer & & & $-^{c}$ & 0.719 & & & $-^{c}$ & 0.056 \\
\hline Yes & $46(82.1)$ & $18(85.7)$ & & & $51(87.9)$ & $13(68.4)$ & & \\
\hline No & $8(14.3)$ & $2(9.5)$ & & & $5(8.6)$ & $5(26.3)$ & & \\
\hline Quality of communication with & & & & & & & & \\
\hline doctors & $3.43 \pm 0.63^{\mathrm{a}}$ & $3.25 \pm 0.89^{\mathrm{a}}$ & $0.79^{\mathrm{b}}$ & 0.439 & $3.36 \pm 0.73^{\mathrm{a}}$ & $3.43 \pm 0.65^{\mathrm{a}}$ & $0.33^{\mathrm{b}}$ & 0.740 \\
\hline \multicolumn{9}{|l|}{ Psychological factors } \\
\hline Optimism & $3.34 \pm 0.85^{\mathrm{a}}$ & $2.85 \pm 0.99^{\mathrm{a}}$ & $2.09^{\mathrm{b}}$ & 0.040 & $3.22 \pm 0.83^{\mathrm{a}}$ & $3.17 \pm 1.15^{\mathrm{a}}$ & $0.21^{\mathrm{b}}$ & 0.837 \\
\hline Numeracy & $2.30 \pm 1.48^{\mathrm{a}}$ & $1.86 \pm 1.59^{\mathrm{a}}$ & $1.16^{\mathrm{b}}$ & 0.251 & $2.33 \pm 1.54^{\mathrm{a}}$ & $1.74 \pm 1.37^{\mathrm{a}}$ & $1.49^{\mathrm{b}}$ & 0.140 \\
\hline Self-efficacy for health management & $4.09 \pm 1.00^{\mathrm{a}}$ & $3.45 \pm 1.05^{\mathrm{a}}$ & $2.43^{\mathrm{b}}$ & 0.018 & $4.05 \pm 2.76^{\mathrm{a}}$ & $3.47 \pm 1.28^{\mathrm{a}}$ & $2.06^{\mathrm{b}}$ & 0.043 \\
\hline \multicolumn{9}{|l|}{ Perceived ambiguity in cancer } \\
\hline prevention recommendations & $2.87 \pm 0.88^{\mathrm{a}}$ & $2.95 \pm 0.91^{\mathrm{a}}$ & $0.34^{\mathrm{b}}$ & 0.739 & $2.76 \pm 0.89^{\mathrm{a}}$ & $3.28 \pm 0.75^{\mathrm{a}}$ & $2.22^{\mathrm{b}}$ & 0.030 \\
\hline Cancer prevention fatalism & $2.17 \pm 1.08^{\mathrm{a}}$ & $2.17 \pm 0.86^{\mathrm{a}}$ & $0.00^{\mathrm{b}}$ & 1.000 & $1.96 \pm 0.88^{\mathrm{a}}$ & $2.74 \pm 1.19^{\mathrm{a}}$ & $2.59^{\mathrm{b}}$ & 0.016 \\
\hline \multicolumn{9}{|l|}{ Trusts health information from } \\
\hline family members & $2.76 \pm 0.78^{\mathrm{a}}$ & $2.70 \pm 0.73^{\mathrm{a}}$ & $0.27^{\mathrm{b}}$ & 0.768 & $2.73 \pm 0.67^{\mathrm{a}}$ & $2.78 \pm 1.00^{\mathrm{a}}$ & $-^{c}$ & 0.716 \\
\hline $\begin{array}{l}\text { Trusts health information from } \\
\text { doctors }\end{array}$ & $3.64+0.59^{\mathrm{a}}$ & $3.25 \pm 0.85^{\mathrm{a}}$ & $2.27^{\mathrm{b}}$ & 0.026 & $3.61+0.56^{\mathrm{a}}$ & $3.32+0.95^{\mathrm{a}}$ & $1.30^{\mathrm{b}}$ & 0.207 \\
\hline $\begin{array}{l}\text { Perceived value of family health } \\
\text { history }\end{array}$ & & & $--^{c}$ & 0.484 & & & $0.09^{\mathrm{b}}$ & 0.762 \\
\hline Yes & $48(85.7)$ & $17(81.0)$ & & & $50(86.2)$ & $15(79.0)$ & & \\
\hline No & $7(12.5)$ & $4(19.0)$ & & & $8(13.8)$ & $3(15.8)$ & & \\
\hline
\end{tabular}

${ }^{a}$ Mean age \pm SD , years. ${ }^{b} t$ test value.${ }^{c}$ Fisher's exact test computed because at least 1 cell had an expected count $<5 .{ }^{\mathrm{d}}$ Because of low cell sizes, the statistical difference test was calculated as income USD $<35,000$ versus $>35,000$. ${ }^{e}$ Because of low cell sizes, the statistical difference test was calculated as non-Hispanic White participants versus all others.

Correlates of Sharing Cancer Genetic Test Results
Public Health Genomics 2015;18:67-77 
mendations for these genetic tests, we cannot conclude whether this level of uptake is medically appropriate. However, the $2.42 \%$ statistic of self-reported uptake of $B R C A 1 / 2$ and Lynch syndrome genetic testing can be compared to estimates in future population-based surveys to determine changes in trends.

Several sociodemographic factors have been associated with greater awareness of cancer or DTC genetic testing, including being White, middle-aged, female, having a personal or family history of cancer, and having health insurance $[29,31]$. Our findings that individuals who had $B R C A 1 / 2$ or Lynch syndrome genetic testing were more likely to be female, to have a family or personal history of cancer, or to have health insurance, compared to those who did not have cancer genetic testing, are consistent with these previous findings. In the present study, the greater prevalence of women undergoing testing is likely due at least in part to the greater uptake of $B R C A 1 / 2$ testing among women compared to men [32], even though $B R C A 1 / 2$ mutations occur at the same rate among men and women [33]. We did not observe differences by education, income, or race/ethnicity that were previously reported. Given the small number of individuals who reported having had genetic testing, these analyses should be considered exploratory, and it would be premature to conclude that disparities in awareness will not be present in uptake.

Our analyses indicated that most participants shared their results with either a health professional or a family member, with only $4 \%$ not sharing their results with anyone. Although limited work has examined whether individuals share genetic test results with physicians, the $75 \%$ rate of sharing information with health professionals in the present study was higher than the $27-40 \%$ of Navigenics consumers who shared their DTC results with their own healthcare provider $[6,11]$. This higher level of disclosure may have occurred if respondents in the present study received genetic testing from a healthcare professional rather than through DTC testing, or if participants had different interpretations of the importance of results from different sources. Another explanation for the lower prevalence of sharing in prior research is that people may seek DTC testing if they do not want to share the results with their physicians, for example, if they are concerned about insurance discrimination. In the present study, fewer respondents may have received DTC results. A limitation of the present study is that we do not know with which kinds of health professionals participants shared their results, or the context in which they received genetic testing.
A larger body of evidence has accumulated relating to the process of disseminating test results within families than with health professionals $[4,22,34-36]$. The high rate of sharing test results with family members was consistent with prior research in which $99 \%$ of respondents shared their results [36], which is expected because a major motivation for undergoing genetic testing is to obtain risk information for family members, particularly for one's children [22]. Importantly, we do not know how many and which relatives were informed, including whether participants informed biological family members as opposed to spouses or other nonbiological relatives. Therefore, rates of sharing with family members may overrepresent whether respondents informed biological family members who stand to potentially benefit medically from knowing this information. Research that examines what specific information is communicated, whether it is communicated accurately, whether it leads to behavior change or genetic testing uptake, and whether or how transmission of this information affects family relationships and dynamics is important to fully understand the social implications of genetic testing. Innovative methods, such as those utilizing pedigrees to map family relationships and channels of communication, may help to elucidate the processes related to communication $[37,38]$.

In the present study, lower self-efficacy for managing one's health was associated with a lower likelihood of communicating results to both health professionals and family members. Self-efficacy is an important component of health behavior theories and an important predictor of greater engagement in health behaviors [39-42]. Our finding is consistent with prior research, in which participant concerns about whether they would be able to accurately relay technical risk information $[22,36]$ and lower self-efficacy for coping with test results [12] were deterrents to sharing genetic test results. In the present study, participants with lower self-efficacy may have believed that they would not be able to accurately relay the risk information. Another explanation is that participants with lower self-efficacy may have felt that others would similarly be unable to effectively use and benefit from the information conferred by a genetic test result. Given the cross-sectional nature of the survey, however, it is unknown whether participants with higher self-efficacy were more likely to share results, or whether sharing one's results led to greater self-efficacy for health management. If self-efficacy does predict sharing, it is important to note that self-efficacy is an intervenable factor. Genetic counselors providing test results could use a single item DOI: $10.1159 / 000368745$
Taber/Chang/Lam/Gillanders/Hamilton/ Schully 
to assess self-efficacy to identify patients who could benefit from further information or resources about how to effectively communicate their results. We also found that participants who perceived greater ambiguity in cancer prevention recommendations were less likely to share their test results, and this construct may similarly be an indicator that people have trouble understanding health information.

Lower numeracy is often associated with negative health outcomes [43] and is associated with lower awareness of genetic testing [31] and less understanding of genetic risk information and test results [44-46]. However, numeracy was not associated with sharing results in the present study. The discordance between our findings and the literature on numeracy may be partially explained by the way numeracy is measured. Our study used an objective measure of numeracy through a series of math-related questions. Other studies have used subjective measures of numeracy, assessed by participants' self-ratings of their own math-related abilities. The latter may be a better predictor of sharing than objective numeracy, as it may also capture a component of whether patients believe they will be able to understand and effectively communicate results.

We identified some differences among factors associated with sharing results with health professionals versus family members. Specifically, greater optimism and trusting health information from doctors were only associated with sharing results with health professionals, whereas greater cancer prevention fatalism was only associated with a lower likelihood of sharing results with family members. These findings represent avenues for future research and should be replicated given the small sample size.

There are several limitations of the present study. First, the cross-sectional survey design prevents drawing causal conclusions. Next, the small sample size precludes drawing strong conclusions concerning differences among those who did and did not undergo BRCA1/2 or Lynch syndrome genetic testing, and concerning factors associated with sharing test results. Findings should be viewed as hypothesis-generating given the large number of statistical comparisons in the small sample.

The small sample also precluded testing whether the pattern of relationships among variables differed according to $B R C A 1 / 2$ testing or Lynch syndrome testing. Because more respondents had undergone $B R C A 1 / 2$ than Lynch syndrome testing, the data are likely more representative of individuals undergoing $B R C A 1 / 2$ testing. It is possible that differences in sharing of test results exist

Correlates of Sharing Cancer Genetic Test Results across these 2 hereditary cancer syndromes. There are similarities between $B R C A 1 / 2$ and Lynch syndrome (i.e. population prevalence of 1 in 400; autosomal dominant patterns of inheritance; the potential to receive uncertain or uninformative genetic test results; lifetime cancer risks of up to $80 \%$ for the primary cancer (breast or colon, respectively) and smaller risks for multiple cancers; recommended screening beginning at 25 years of age) [47]. But, Lynch syndrome testing can involve both tumor tissue testing (e.g. microsatellite instability testing and/or immunohistochemistry) and mutation testing, which can potentially lead to uncertain results and/or discordant results across these tests [48]. Thus, individuals undergoing Lynch syndrome testing may be subject to greater clinical uncertainty about their risk status, which may influence how likely they are to share their results with physicians or family members.

Another limitation is the substantial number of people that provided inconsistent responses to the item about genetic testing and with whom they shared results. Up to an additional 58 participants may have received $B R C A 1 / 2$ or Lynch syndrome genetic testing. However, we can only be confident that 77 participants did in fact receive genetic testing. Unfortunately, we do not know from whom or why participants received results, or the specific test results participants received (patterns of sharing differ based on whether one is a mutation carrier, noncarrier, or receives inconclusive results $[13,16,17])$. A final limitation is the use of a single item that assessed only one component of cancer fatalism, rather than a validated scale.

In addition to the tangible benefits for family members in terms of obtaining genetic testing for themselves, sharing genetic test results can be beneficial if it allows the patient to receive social support $[17,35]$. Thus, understanding predictors of sharing genetic test results is an important avenue for future research, particularly as genetic testing becomes increasingly available to the general public outside of the context of research or a physician's recommendation. The present data shed light on factors related to this process among respondents from a national survey. Following confirmation in larger samples (for example, if nationally representative surveys with more respondents, such as the National Health Interview Study, were to assess genetic testing uptake in detail), results from this study may help to identify patients who are less likely to share information with their at-risk family members and with healthcare providers who can assist them with disease management. 


\section{References}

1 Daly MB, Axilbund JE, Buys S, Crawford B, Farrell CD, Friedman S, Garber JE, Goorha S, Gruber SB, Hampel H, Kaklamani V, Kohlmann W, Kurian A, Litton J, Marcom PK, Nussbaum R, Offit K, Pal T, Pasche B, Pilarski R, Reiser G, Shannon KM, Smith JR, Swisher E, Weitzel JN; National Comprehensive Cancer Network: Genetic/familial high-risk assessment: breast and ovarian. J Natl Compr Canc Netw 2010;8:562-594.

-2 Evaluation of Genomic Applications in Practice and Prevention (EGAPP) Working Group: Recommendations from the EGAPP working group: Genetic testing strategies in newly diagnosed individuals with colorectal cancer aimed at reducing morbidity and mortality from Lynch syndrome in relatives. Genet Med 2009;11:35-41.

-3 Moyer VA; U.S. Preventive Services Task Force: Risk assessment, genetic counseling, and genetic testing for BRCA-related cancer in women: U.S. Preventive services task force recommendation statement. Ann Intern Med 2014;160:271-281.

-4 Gaff CL, Clarke AJ, Atkinson P, Sivell S, Elwyn G, Iredale R, Thornton H, Dundon J, Shaw C, Edwards A: Process and outcome in communication of genetic information within families: a systematic review. Eur J Hum Genet 2007;15:999-1011.

5 Francke U, Dijamco C, Kiefer AK, Eriksson N, Moiseff B, Tung JY, Mountain JL: Dealing with the unexpected: consumer responses to direct-access $B R C A$ mutation testing. Peer J 2013;1:e8.

-6 Bloss CS, Wineinger NE, Darst BF, Schork NJ, Topol EJ: Impact of direct-to-consumer genomic testing at long term follow-up. J Med Genet 2013;50:393-400.

7 Kaphingst KA, McBride CM, Wade C, Alford SH, Reid R, Larson E, Baxevanis AD, Brody LC: Patients' understanding of and responses to multiplex genetic susceptibility test results. Genet Med 2012;14:681-687.

8 Kaufman DJ, Bollinger JM, Dvoskin RL, Scott JA: Risky business: risk perception and the use of medical services among customers of DTC personal genetic testing. J Genet Couns 2012; 21:413-422.

-9 Kinney AY, Simonsen SE, Baty BJ, Mandal D, Neuhausen SL, Seggar K, Holubkov R, Bloor L, Smith K: Risk reduction behaviors and provider communication following genetic counseling and BRCA1 mutation testing in an African American kindred. J Genet Couns 2006; 15:293-305.

10 Ready K, Arun BK, Schmeler KM, Uyei A, Litton JK, Lu KH, Sun CC, Peterson SK: Communication of $B R C A 1$ and $B R C A 2$ genetic test results to health care providers following genetic testing at a tertiary care center. Fam Cancer 2011;10:673-679.

11 Darst BF, Madlensky L, Schork NJ, Topol EJ, Bloss CS: Characteristics of genomic test consumers who spontaneously share results with their health care provider. Health Commun 2014;29:105-108.

12 Graves KD, Sinicrope PS, Esplen MJ, Peterson SK, Patten CA, Lowery J, Sinicrope FA, Nigon SK, Borgen J, Gorin SS, Keogh LA, Lindor NM; Behavioral Working Group of the Colon Cancer Family Registry: Communication of genetic test results to family and health-care providers following disclosure of research results. Genet Med 2014;16:294-301.

13 DeMarco TA, McKinnon WC: Life after BRCA1/2 testing: family communication and support issues. Breast Dis 2006;27:127-136.

14 Lafrenière D, Bouchard K, Godard B, Simard J, Dorval M: Family communication following BRCA1/2 genetic testing: a close look at the process. J Genet Couns 2013;22:323-335.

15 Bleiker EM, Esplen MJ, Meiser B, Petersen HV, Patenaude AF: 100 years Lynch syndrome: what have we learned about psychosocial issues? Fam Cancer 2013;12:325-339.

16 Claes E, Evers-Kiebooms G, Boogaerts A, Decruyenaere M, Denayer L, Legius E: Communication with close and distant relatives in the context of genetic testing for hereditary breast and ovarian cancer in cancer patients. Am J Med Genet A 2003;116A:11-19.

17 Stoffel EM, Ford B, Mercado RC, Punglia D, Kohlmann W, Conrad P, Blanco A, Shannon KM, Powell M, Gruber SB, Terdiman J, Chung DC, Syngal S: Sharing genetic test results in Lynch syndrome: communication with close and distant relatives. Clin Gastroenterol Hepatol 2008;6:333-338.

18 Cheung EL, Olson AD, Yu TM, Han PZ, Beattie MS: Communication of $B R C A$ results and family testing in 1,103 high-risk women. Cancer Epidemiol Biomarkers Prev 2010;19: 2211-2219.

19 Fehniger J, Lin F, Beattie MS, Joseph G, Kaplan C: Family communication of BRCA1/2 results and family uptake of $B R C A 1 / 2$ testing in a diverse population of $B R C A 1 / 2$ carriers. J Genet Couns 2013;22:603-612.

20 Finlay E, Stopfer JE, Burlingame E, Evans KG, Nathanson KL, Weber BL, Armstrong K, Rebbeck TR, Domchek SM: Factors determining dissemination of results and uptake of genetic testing in families with known BRCA1/2 mutations. Genet Test 2008;12:8191.

21 Mesters I, Ausems M, Eichhorn S, Vasen H: Informing one's family about genetic testing for hereditary non-polyposis colorectal cancer (HNPCC): a retrospective exploratory study. Fam Cancer 2005;4:163-167.

22 Seymour KC, Addington-Hall J, Lucassen AM, Foster CL: What facilitates or impedes family communication following genetic testing for cancer risk? A systematic review and meta-synthesis of primary qualitative research. J Genet Couns 2010;19:330-342.

23 Dancyger C, Wiseman M, Jacobs C, Smith JA, Wallace M, Michie S: Communicating $B R C A 1 / 2$ genetic test results within the fam- ily: a qualitative analysis. Psychol Health 2011;26:1018-1035.

24 National Cancer Institute: Health Information National Trends Survey 4 (HINTS 4) Cycle 3 methodology report. 2014.

25 Scheier MF, Carver CS, Bridges MW: Distinguishing optimism from neuroticism (and trait anxiety, self-mastery, and self-esteem): a reevaluation of the Life Orientation Test. J Pers Soc Psychol 1994;67:1063-1078.

26 Weiss BD, Mays MZ, Martz W, Castro KM, DeWalt DA, Pignone MP, Mockbee J, Hale FA: Quick assessment of literacy in primary care: the newest vital sign. Ann Fam Med 2005;3:514-522.

27 Klein WM, Ferrer RA, Graff KA, Kaufman AR, Han PK: Perceived ambiguity, fatalism, and believing cancer is more prevalent than heart disease. Am J Prev Med 2014;46:e45e47.

28 Espinosa de Los Monteros K, Gallo LC: The relevance of fatalism in the study of Latinas' cancer screening behavior: a systematic review of the literature. Int J Behav Med 2011; 18:310-318.

29 Mai PL, Vadaparampil ST, Breen N, McNeel TS, Wideroff L, Graubard BI: Awareness of cancer susceptibility genetic testing: the 2000 , 2005, and 2010 National Health Interview Surveys. Am J Prev Med 2014;46:440-448.

30 Finney Rutten LJ, Gollust SE, Naveed S, Moser RP: Increasing public awareness of directto-consumer genetic tests: health care access, internet use, and population density correlates. J Cancer Epidemiol 2012;2012:309109.

- 31 Langford AT, Resnicow K, Roberts JS, Zikmund-Fisher BJ: Racial and ethnic differences in direct-to-consumer genetic tests awareness in HINTS 2007: sociodemographic and numeracy correlates. J Genet Couns 2012;21: 440-447.

32 Daly MB: The impact of social roles on the experience of men in BRCA1/2 families: implications for counseling. J Genet Couns 2009; 18:42-48.

33 Ford D, Easton DF, Stratton M, Narod S, Goldgar D, Devilee P, Bishop DT, Weber B, Lenoir G, Chang-Claude J, Sobol H, Teare MD, Struewing J, Arason A, Scherneck S, Peto J, Rebbeck TR, Tonin P, Neuhausen S, Barkardottir R, Eyfjord J, Lynch H, Ponder BA, Gayther SA, Zelada-Hedman M, et al: Genetic heterogeneity and penetrance analysis of the $B R C A 1$ and $B R C A 2$ genes in breast cancer families. The breast cancer linkage consortium. Am J Human Genet 1998;62:676-689.

34 Peterson SK: The role of the family in genetic testing: theoretical perspectives, current knowledge, and future directions. Health Educ Behav 2005;32:627-639.

- 35 Wilson BJ, Forrest K, van Teijlingen ER, McKee L, Haites N, Matthews E, Simpson SA: Family communication about genetic risk: the little that is known. Community Genet 2004;7:15-24. 
36 Montgomery SV, Barsevick AM, Egleston BL, Bingler R, Ruth K, Miller SM, Malick J, Cescon TP, Daly MB: Preparing individuals to communicate genetic test results to their relatives: report of a randomized control trial. Fam Cancer 2013;12:537-546.

- 37 Koehly LM, Peters JA, Kenen R, Hoskins LM, Ersig AL, Kuhn NR, Loud JT, Greene MH: Characteristics of health information gatherers, disseminators, and blockers within families at risk of hereditary cancer: implications for family health communication interventions. Am J Public Health 2009;99:2203-2209.

38 Smith JA, Dancyger C, Wallace M, Jacobs C, Michie S: The development of a methodology for examining the process of family communication of genetic test results. J Genet Couns 2011;20:23-34.

39 Bandura A: Social cognitive theory: an agentic perspective. Annu Rev Psychol 2001;52:1-26.
40 Bandura A: Health promotion by social cognitive means. Health Educ Behav 2004;31: 143-164.

41 Floyd DL, Prentice-Dunn S, Rogers RW: A meta-analysis of research on protection motivation theory. J Appl Soc Psychol 2000;30: 407-429.

42 Rodgers WM, Conner M, Murray TC: Distinguishing among perceived control, perceived difficulty, and self-efficacy as determinants of intentions and behaviours. Br J Soc Psychol 2008;47:607-630.

43 Nelson W, Reyna VF, Fagerlin A, Lipkus I, Peters E: Clinical implications of numeracy: theory and practice. Ann Behav Med 2008;35: 261-274.

44 Hanoch Y, Miron-Shatz T, Rolison JJ, Ozanne $\mathrm{E}$ : Understanding of $\mathrm{BRCA} 1 / 2$ genetic tests results: the importance of objective and subjective numeracy. Psychooncology 2014;23: $1142-1148$
45 Rolison JJ, Hanoch Y, Miron-Shatz T: What do men understand about lifetime risk following genetic testing? The effect of context and numeracy. Health Psychol 2012;31:530-533.

46 Lea DH, Kaphingst KA, Bowen D, Lipkus I, Hadley DW: Communicating genetic and genomic information: health literacy and numeracy considerations. Public Health Genomics 2011;14:279-289.

47 Aspinwall LG, Taber JM, Kohlmann W, Leachman SA: Genetic counseling and cancer; in Carr BI, Steel J (eds): Psychological Aspects of Cancer: A Guide to Emotional and Psychological Consequences of Cancer, their Causes and their Management. New York, Springer, 2013, pp 61-64.

48 Gallagher DJ, Smith JD, Offit K, Stadler ZK: Diagnosing hereditary colorectal cancer. Clin Colorectal Cancer 2010;9:205-211. 